\title{
Modified Puestow procedure for relapsing pancreatitis in a 2 years old girl
}

\section{Ezer SS* and Temiz A}

Baskent University School of Medicine, Adana Teaching and Research Center, Department of Pediatric Surgery, Adana, Turkey

Sir,

Chronic relapsing (RP) pancreatitis is rare in childhood but can have serious results $[1,2]$. RP leads fibrosis which makes progressive endocrine and exocrine dysfunction of pancreas [2-4]. The underlying pathologies can be hereditary pancreatitis, post traumatic stenosis and congenital developmental anomalies such as pancreatic divisum, pancreaticobiliary duct anomalies [1,2,3,4]. An appropriate ductal drainage procedure is necessary for relief of symptoms [3,4]. Here, we presented a malnourished infantwith relapsing pancreatitis with marked growth retardation.

A-2-year old, 8000gr ( $<3 \mathrm{p})$ female was admitted with abdominal pain for 45 days without history of trauma. She had been treated for bilateral pleural effusion and pancreatic cysts at another institution with no improvement. Her physical examination was unremarkable. Laboratory tests were as follow: $\mathrm{Hb}: 8 \mathrm{mg} / \mathrm{dl}$, CRP: $167 \mathrm{mg} / \mathrm{dl}$, Amylase: $161 \mathrm{U} / \mathrm{L}$, Lipase: 355U/L. Computed tomography revealed, dilated pancreatic duct and $5 \times 6 \mathrm{~cm}$ in sized peripancreatic fluid (Figure 1A). Concomitantly venous cavernous transformation was reported in the portal hylus. Percutaneous drainage catheter was inserted, and parenteral nutrition was given. Sphincterotomy was done via ERCP (endoscopic retrograde cholangiopancreatography). She was discharged on $20^{\text {th }}$ day uneventfully. Unfortunately, she was readmitted 2 weeks later for abdominal pain and feeding intolerance. Ultrasound revealed peripancreatic fluid and cavernous transformation of portal vein. Laboratory tests were as follow: Amylase 189U/L, Lipase 1000U/L,Hb: 7.4mg/dl. Magnetic Resonance Imaging revealed bilateral pleural effusion and dilated pancreatic duct with peripancreatic edema and fluid collection. Bilateral percutaneous drainage was performed. She was considered having relapsing pancreatitis. Modified Puestow procedure (lateral pancreaticojejunostomy) was performed (Figure 1B). Post-operative period was uneventful. Three weeks later, her improvement in nutritional status, and gaining weight (9300gr) was observed. Six months later she was free of symptoms and 12500gr (25$50 \mathrm{p})$ in weight, Amylase and Lipase were normal in limit. She referred for regular gastroenterological follow-up for persisted portal venous cavernous transformation.

Chronic pancreatitis presents with recurrent abdominal pain, feeding intolerance, growth retardation peripancreatic/pleural fluid collection and elevated amylase/lipase levels $[4,5]$. Treatment modalities depend on etiological factors and patient's clinical status. Clinicians consider to drainage of pancreatic duct for relieving symptoms and catching up the physiological development [1,2.5]. Imaging studies should clarify the anatomy of the pancreas and dilated pancreatic duct for deciding proper patient-based treatment $[4,5]$. If possible, firstly, ERCP is indicated to identify dilated pancreatic duct and interventions
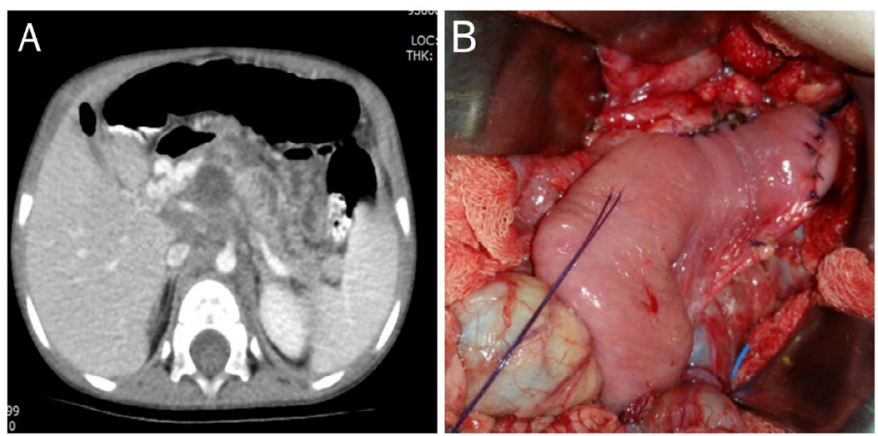

Figure 1. A. Marked dilated pancreatic duct and regional fluid collection B. Performed modified Puestowprocedure

for drainage. Pancreaticojejunal anastomosis are performed by using different reported technique when ERCP is insufficient or impossible $[1,2,3]$. In our case, papillotomy was done via ERCP firstly to relief her symptoms but 2 weeks later she returned with episode of pancreatitis (bilateral hydrothorax, abdominal pain) without gaining weight. She required undergoing for pancreatic duct decompression. We determined an appropriate surgical drainage procedure. She underwent lateral pancreaticojejunostomy (Partington-Rochelle, modified Puestow procedure) [5]. Surgery should be performed timely before pancreatic fibrosis develops resulting recurrent pancreatic attack to preserve exocrine and endocrine function of pancreas in childhood. Because spleen carries essential role for childhood, we performed modified Puestow procedure in which tail of pancreas and spleen are spared without further damage. Appropriate surgery should be arranged to prevent complications of relapsing pancreatitis that resulting disturbance of pancreatic function further. When dealing with recurrent pancreatitis, these patients should be monitored regularly for the functions of the pancreas and the development of portal hypertension.

\section{References}

1. Crombleholme TM, deLorimier AA, Way LW, Adzick NS, Longaker MT, et al.(1990) The modified Puestow procedure for chronic relapsing pancreatitis in children. $J$ Pediatr Surg 25: 749-54. [Crossref]

${ }^{\star}$ Correspondence to: Ezer SS, Baskent University School of Medicine, Adana Teaching and Research Center, Department of Pediatric Surgery, Adana, Turkey, Tel: + 90 (533) 2583929; Fax: + 90 (322) 3271279; E-mail: semireserin@yahoo.com

Key words: childhood pancretitis, modified puestow procedure

Received: February 14, 2019; Accepted: February 21, 2019; Published: February 25, 2019 
2. Kargl S, Kienbauer M, Duba HC, Schöfl R, Pumberger W (2015) Therapeutic step-up strategy for management of hereditary pancreatitis in children. J Pediatr Surg 50: 511514. [Crossref]

3. Laje P, Adzick NS (2013) Modified Puestow procedure for the management of chronic pancreatitis in children. J Pediatr Surg 48: 2271-2275. [Crossref]
4. Clifton MS, Pelayo JC, Cortes RA, Grethel EJ, Wagner AJ, et al. (2007) Surgical treatment of childhood recurrent pancreatitis. J Pediatr Surg 42: 1203-1207. [Crossref]

5. O'Neil SJ, Aranha GV (2003) Lateral pancreaticojejunostomy for chronic pancreatitis. World J Surg 27: 1196-1202. [Crossref]

Copyright: (O2019 Ezer SS. This is an open-access article distributed under the terms of the Creative Commons Attribution License, which permits unrestricted use, distribution, and reproduction in any medium, provided the original author and source are credited. 